\title{
Dipteran diversity and succession pattern on carcass of rabbits treated with opium dross: Implication in forensic medicine
}

\author{
DAVOOD KESHAVARZ ${ }^{1}$, YAVAR RASSI ${ }^{1, \bullet}$, MOHAMADALI OSHAGHI $^{1}$, KOUROSH AZIZI $^{2}$, \\ SAYENA RAFIZADEH ${ }^{3}$, MARZIEA SHAHRIARINAMADI ${ }^{2}$ \\ ${ }^{1}$ Department of Medical Entomology and Vector Control, School of Public Health, Tehran University of Medical Sciences. Tehran, Iran. \\ vemail: rassiy@tums.ac.ir \\ ${ }^{2}$ Research Center for Health Sciences, Institute of Health, Department of Medical Entomology and Vector Control, School of Health, Shiraz University of \\ Medical Sciences. Shiraz, Iran \\ ${ }^{3}$ Ministry of Health and Medical Education, Tehran, Iran
}

Manuscript received: 12 March 2020. Revision accepted: 18 June 2020.

\begin{abstract}
Keshavarz D, Rassi Y, Oshaghi MA, Azizi K, Rafizadeh S, Shahriarinamadi M. 2020. Dipteran diversity and succession pattern on carcass of rabbits treated with opium: Implication in forensic medicine. Biodiversitas 21: 3135-3141. The present study aimed to investigate the effect of opium on the succession pattern and diversity of Diptera on rabbit carcasses. In the present experimental study, dipteran species were collected from rabbit carcasses during the decay process. During this study, two replicates were performed, and four rabbits were used in each. Rabbits divided equally into two groups. In the first group, animals were received $25 \mathrm{mg}$ opium dross orally via a gastric tube and then gradually increased the dose to $100 \mathrm{mg} /$ case/day, while the second group were used as controls and received distilled water. The most frequent species on both carcass types were Chrysomya albiceps (26.2\%), Lucilia sericata (15.9\%), and Musca domestica (13.9\%). Diversity analysis indicates high species richness on untreated carcasses (Shannon: 2.1; Margalef: 1.7). However, a significant difference was not detected for the Shannon index between the treated and untreated carcasses (P: 0.56). The taxa similarity values for sampling intervals ranged from $0.20-0.46$ for both untreated and treated carcasses. Permutation analysis showed that successional patterns of dipteran species were similar between opium dross-treated and untreated carcasses. Therefore, in the case of opioid (opium) abused cadaver, this substance could not have an effect on the PMI estimation based on the pattern of succession. But it seems that the PMI should be corrected when the estimate is based on larval growth rate.
\end{abstract}

Keywords: Diptera, diversity, Iran, opium dross, succession pattern

\section{INTRODUCTION}

Substance abuse is excessive use of alcohol or drugs in a manner that is dangerous to self or others (Concheiro et al. 2018; Siste et al. 2019). Drug misuse is a serious health problem worldwide, and its frequency expected to rise (Concheiro et al. 2018; Sugihartati and Susilo 2019). The term "opioids" technically refers to natural products derived from the opium poppy (Papaver somniferum), semisynthetic and synthetic derivatives of opiates that bind to opioid receptors in the brain and produce morphine-like effects (Campos-Manas et al. 2019). Certain types of opioids such as; Clonidine, Buprenorphine, Methadone, Codeine, Fentanyl, Morphine, and opium tincture are prescribed for the treatment of opioid use disorder and also treat acute and chronic pain (Jamalian et al. 2019; Oesterle et al. 2020).

Opium contains approximately $20-25 \%$ alkaloids, including Morphine, Noscapine, Codeine, Thebaine, Narceine, Papaverine, and Hydrocotarnine that affects the central nervous system, and also the respiratory and cardiovascular systems (Dahmardehei and Rafaiee 2012; Moezi et al. 2019; Li et al. 2020). Afghanistan is the biggest producer of opium in the world, and Iran is a major route of opium transportation. Consequently, the availability and use of opium are major issues in Iran (Alinejad et al. 2018; Jamalian et al. 2019).
More than 2900 deaths due to opioids (opium alkaloids, opium, synthetic prescription opioids, and other illegal opioids) misuse have been reported in Iran during March 2014 to February 2015 (Shahbazi et al. 2017). In a number of drug-related deaths, the corpse is found after a few days or weeks when the decomposition process is in its mid or late stages. In such cases, medico-legal entomology as a reliable scientific discipline, utilize entomological evidence to determine the location of death, detection of the abuse of disabled people, identification of the deceased, and estimate the PMI (Gemmellaro et al. 2019; Magni et al. 2019; Wang et al. 2019). The entomological evidence to estimate the time elapsed since death consists of two main approaches; the estimate based on the largest available larvae developed on the corpse (minPMI) and one based on the succession patterns. Development time of the largest larvae on the corpse is the most commonly used entomological method for the estimation of PMI, especially in cases where the time elapsed since death is short (Bugelli et al. 2018). However, each of these methods has weaknesses, and their accuracy could be affected by several factors such as; temperatures, drugs, wrapping, size, and location of the carcass (Tabor et al. 2005). Dipteran species colonize the corpse predictability; as blowflies (Diptera: Calliphoridae) are mainly found in the early phases of body decomposition, flesh flies (Diptera: 
Sarcophagidae) and Muscidae in the middle stages of body decomposition, Piophilidae and Sepsidae in the last stages of body decay (Tabor et al. 2005; Gemmellaro et al. 2019; Magni et al. 2019). Blowflies frequently used to estimate a minimum post-mortem interval (Gemmellaro et al. 2019). But, the utility of flesh flies has been seriously hindered by limited biological and taxonomic data of them (Ren et al. 2018).

Most medico-legal entomological succession studies around the world are carried out using pig or rabbit carcasses. However, the use of stout pigs $(23-27 \mathrm{~kg}$ ) is preferable (Wang et al. 2017). Unfortunately, it was not possible to provide pigs in the country. So, we decided to use rabbits as an animal model. Investigating the effect of different types of drugs on the growth rate and development of forensically important flies showed that; Heroin, Codeine, Methamphetamine, Cocaine decrease larval development time and increase larval growth rate. While, Amitriptyline and Tramadol increase larval development time and increase its growth rate (Goff et al. 1991; El-Samad et al. 2011; Carvalho et al. 2012; Salimi et al. 2018a). Therefore, opioids effects on the development cycle of flies that can be leading to an over- or underestimates of the PMI. Various studies have been conducted to investigate the effects of opioids on species growth rates (Goff et al. 1991; El-Samad et al. 2011; Carvalho et al. 2012; Salimi et al. 2018a), but few on the effects of opioids on successional waves. For example, El-Gawad et al. (2019) reported that adults and larvae of insects were more frequent on the Warfarin-treated carcasses than in the control carcasses. Abouzied (2016) observed that Tramadol treated carcasses are more attractive for females of some fly species. Thus, few published data are available to investigate the effect of the use of antemortem opium on the succession pattern of flies. As a consequence, the objectives of this research are to determine whether antemortem use of opium affects the successional patterns of Diptera on decaying remains and, finally, determine the species diversity and fauna of the local communities of necrophagous flies in the study area.

\section{MATERIALS AND METHODS}

\section{Study area}

The experiment was conducted during October 2019 in the district of Qaemyeh, Fars Province, Southwest of Iran $\left(29^{\circ} 52^{\prime} 0^{\prime \prime} \mathrm{N}, 51^{\circ} 35^{\prime} 0^{\prime \prime} \mathrm{E}\right)$. The district is located at $912 \mathrm{~m}$ above sea level, and it has a subtropical hot semi-arid climate with an average annual temperature of $20.4^{\circ} \mathrm{C}$ and precipitation rate of $260 \mathrm{~mm}$. Climate data were obtained from the closest meteorological stations and from multiple measurements done on the site (Figure 1).

\section{Experimental animal and dosing of opium}

In the present experimental study, two replicates were performed, and four rabbits were used in each. Rabbits (1.6-2.0 kg) obtained from the Animal Lab at Shiraz University of Medical Sciences, divided into two groups, including addicted rabbits and non-addicted or control. The required opium was delivered from Anti-Narcotics Department of Shiraz Police (Iran). All of the animals were maintained on a 12-hour light-dark cycle and unlimited access to food and water. Addicted group was treated with opium dross for 14 consecutive days. They received $25 \mathrm{mg}$ opium dross orally via a gastric tube and then gradually increased the dose to $100 \mathrm{mg} / \mathrm{case} / \mathrm{day}$. In the control group, only distilled water (without opium) was used.

At the end of the period, to ensure that rabbits were opium-addicted, Naloxone (1 mg/kg I.M.) was injected and opiate withdrawal symptoms were observed. In addition, blood samples were taken from the ear vein of rabbits and were analyzed for opium by one step morphine test stripe (Abon ${ }^{\circledR}$, China) (Figure 2). At the end of the treatment period, the animals were killed by chloroform. After confirmation of killing and death occurrence, they were transferred to the outdoor site and placed inside separate cages $\left(75 \times 50 \times 65 \mathrm{~cm}^{3}\right)$ with $2 \mathrm{~cm}$ steel-welded tubing, surrounded by $1.4 \mathrm{~cm}$ of mesh. Most of the day, all the cages received direct sunlight. This experiment was carried out under the guidance of the Ethics Committee of the Tehran University of Medical Sciences (IR.TUMS.SPH.REC.1397.053).

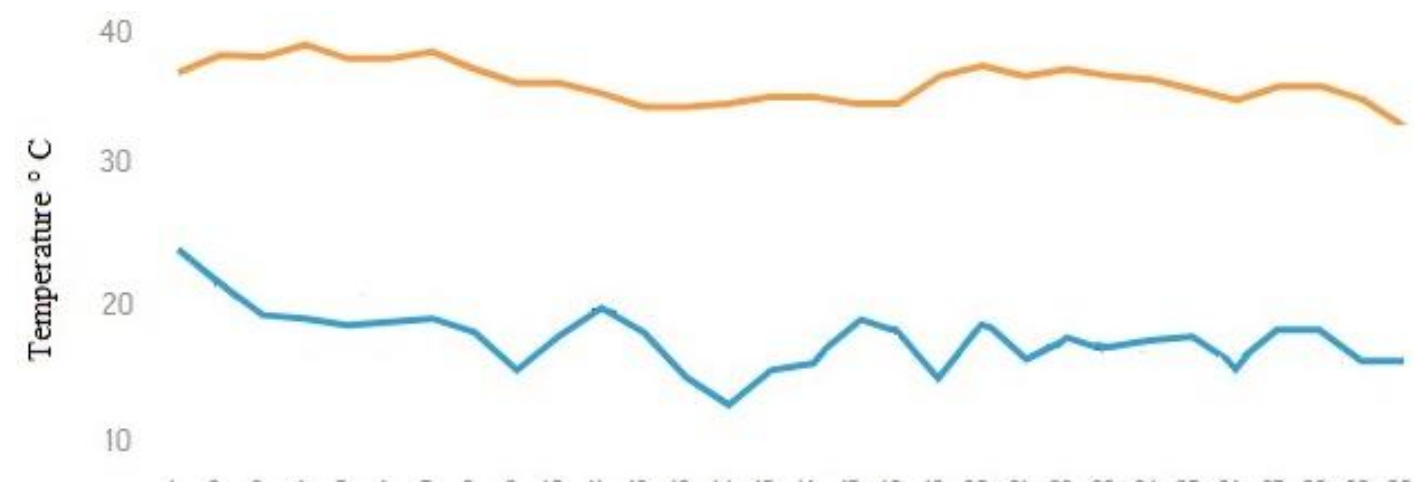

Day 


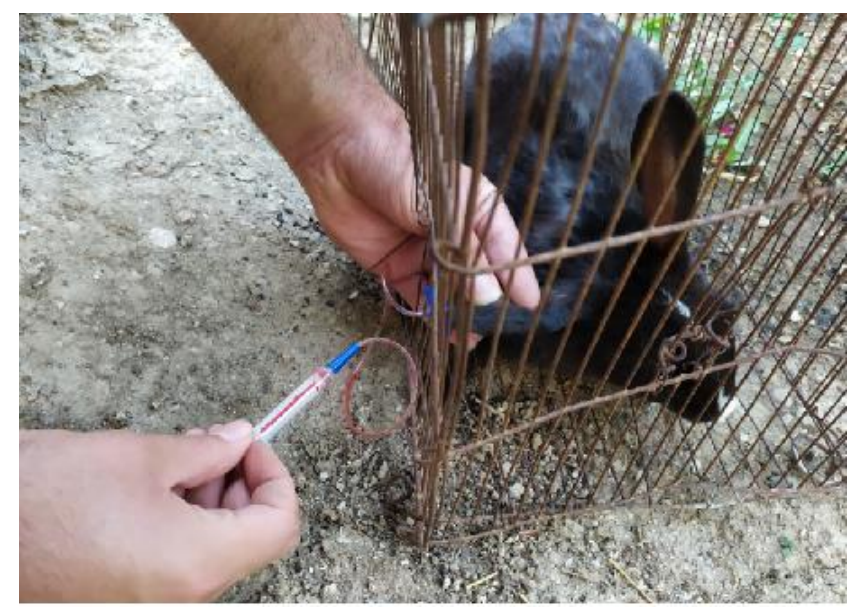

Figure 2. Blood collection from the central ear vein of rabbit model to confirm the presence of opium

\section{Larvae collection and diversity analysis}

Dipteran samples were collected twice daily at 8 am and $4 \mathrm{pm}$, during fresh and blot stages of decomposition and then once per day for the next stages. We collected eggs and larvae from different parts of the carcasses, including; on, underneath, and inside the remains with forceps or by hand, and also we used pitfall traps to catch post-feeding maggots. To make the pitfall trap, we used 16 small plastic cups (4 $\mathrm{cm}$ in diameter) that filled with ethanol. Larvae were separately preserved in categorized plastic containers (labeled by date and carcass case) and transported to the laboratory for rearing and simplicity identification (Akbarzadeh et al. 2015; Szpila et al. 2015). In the laboratory, the collected larvae reared in a blood agar plate (12 larvae per plate) provided with a little damp tissue paper. We used the methods described in Tabor et al. (2004) to characterize the successional patterns of fly taxa on opium-treated and untreated carcasses over the $12 \mathrm{~d}$ sampling period.

Jaccard similarity coefficients were used to determine the species match between sampling intervals within the experimental carcasses. The Jaccard index ranges from 0-1 showing complete dissimilarity to perfectly match the sampling intervals for any insect species (Khoobdel et al. 2020). Average similarities of species between the sampling intervals were calculated for both treated and control groups. In the present study, the H-null hypothesis represents the dissimilarity between the successional waves of species from testing and control carcasses $\left(\mathrm{H}_{0}: P: 0\right)$.

Shannon diversity index ( $\mathrm{H}^{\prime}:-[\Sigma$ (pi lnpi)], where pi: $\mathrm{ni} / \mathrm{N}$ [ni is the number of specimens of taxon i]) was obtained to determine species diversity in each group (Tabor et al. 2005; Keshavarzi et al. 2019). The diversity ttest was used to evaluate the differences between the values of Shannon. The analysis was done with PAST software version 3.14 (Paleontological Statistics Software Package). The accuracy of Jaccard similarity between groups was tested by the Jackknife method (Pi: J + ( $\mathrm{n}-1)\left(\mathrm{J}-\mathrm{J} \mathrm{J}_{\mathrm{i}}\right.$, where $n$ is the number of sampling intervals, $\mathrm{J}$ is the overall resemblance and $\mathrm{J}_{\mathrm{i}}$ is the partial estimate of $\mathrm{J}$ when it sampling interval is removed.

\section{RESULTS AND DISCUSSION}

The present study demonstrated five phases of rabbit carcass decomposition that were fresh, bloated, decay, post decay, dry, and complete decomposition occurred in 19 days. The duration of decomposition processes was similar between treated and untreated carcasses. There was no significant difference between the two replicates in terms of decomposition stages $(\mathrm{P}>0.05)$. In the fresh stage, rigor mortis (a permanent contraction of muscles after death) and algor mortis (cooling of the body after death) were observed. The bloat stage was characterized by the accumulation of gases in the body. Indeed, the interval between the occurrence of death and when the signs of bloat are apparently defined as the fresh stage.

During the decay stage, putrefaction, and liquefaction of carcass tissues were observed. The post decay phase was characterized by the destruction of soft tissues and the appearance of bones. Finally, in the dry stage, the body is reduced to nails, skeleton, and hair. Other scientists who have worked on rabbit models in previous studies reported the same number of stages of rabbit decomposition (Shaalan et al. 2011; Salimi et al. 2018b).

Study on successive waves of flies attracted to Warfarin-intoxicated rabbit carcasses in Cairo, Egypt showed that the decomposition processes were insignificantly faster in treated carcasses than in untreated (El-Gawad et al. 2019). Contrarily, Abouzied (2016), reported that the overall decomposition processes were similar between Tramadol treated and untreated carcasses. A total of 15 species of the four families were collected, all were collected on control carcasses, while 14 species were collected on treated carcasses. The most common species were those of Calliphoridae (61.4\%), Sarcophagidae (16.8\%), Muscidae (20.2\%), and Fannidae (1.6\%).

In general, 966 flies were collected from all treated and control carcasses, more specimens were collected during the decay $(45.2 \%)$. The frequency of specimens in fresh, bloat, post decay, and dry stage of decomposition were $8 \%$, $30 \%$, and $20 \%$, respectively (Table 1 ).

During the fresh stage of decomposition, Chrysomya albiceps was the activist visitors to both carcass types, while Lucilia sericata and Musca domestica as the first visitors were collected only from the remains of treated and untreated rabbits, respectively. They laid eggs in and around the nose, anus, and head of the carcasses. At this stage, more eggs were observed on the untreated carcasses, but the first batch of eggs was found on the treated carcasses and belonged to the Ch. albiceps species. By day 2, Ch. albiceps and L. sericata were presented on both carcass types, while Muscina stabulans and M. domestica were restricted to the remains of treated and untreated rabbit carcasses, respectively. At the end of the day, the first instar of Ch. albiceps was found. Flies attracted to both control and treated remains within 3 hours of death and oviposition was observed about 8 hours later, this observation was in agreement with previous studies (Mashaly et al. 2016; Keshavarzi et al. 2019). 
Table 1. The frequency of dipteran immatures during the different decomposition stages for the opium dross treated and untreated rabbit carcasses, 2019

\begin{tabular}{lccc}
\hline $\begin{array}{c}\text { The stages of } \\
\text { decomposition }\end{array}$ & $\begin{array}{c}\text { Opium dross- } \\
\text { Treated N(\%) }\end{array}$ & $\begin{array}{c}\text { Untreated } \\
\mathbf{N}(\%)\end{array}$ & $\begin{array}{c}\text { Total } \\
\mathbf{N}(\%)\end{array}$ \\
\hline Fresh & $9(53.0)$ & $8(47.0)$ & $17(1.7)$ \\
Bloated & $139(43.5)$ & $180(56.5)$ & $319(33.0)$ \\
Decay & $208(47.7)$ & $228(52.3)$ & $436(45.2)$ \\
Post decay and dry & $92(47.4)$ & $102(52.6)$ & $194(20.1)$ \\
\hline
\end{tabular}

According to the study of Al-mesbah et al (2012) on the decomposition of rabbit carcasses and associated necrophagous diptera in Kuwait, Ch. albiceps is constantly present in the early stages of decomposition. Contrary to the present findings, a study in India showed that Sarcophaga ruficornis is the first visitor in the fresh stage (Hore et al. 2017). Mahat et al. (2009) observed that Malathion generally delayed the initial oviposition of dipteran species. Therefore, the presence of different substances in the remains can lead to different behavior in flies. Martín-Vega et al. (2017) observed that, in each season, flies feed on fresh carcasses within the first 24-48 h and oviposit mainly in the carcass natural orifices.
At the beginning of the bloated stage (day 3), different life stages, including eggs, 1 st and 2 nd instar larvae of Calliphoridae and Muscidae were observed in both carcass types. The first 3rd instar larvae were observed in the untreated carcasses on day 3. During the bloated stage, Calliphora vomitoria and Fannia sp. appeared on the untreated carcasses, while Wohlfahrtia nuba appeared on treated carcasses. By day 5, carcasses were in decay, and very large numbers of immature were present on the treated carcasses. Succession waves of insects on the remains of untreated and treated rabbits for each sampling day are shown in Figures 3.

During the decay stage, the activity of $C$. vicina decreased on opium-treated carcasses, while its activity increased on untreated carcasses. This species was collected together with Ch. megacephala and Ch. albiceps in both carcass types. The presence of $C$. vicina in October was fairly surprising given that this species tends to favor cool weather conditions. These two species occur together on untreated carcasses. Although $C$. vicina prefers urban areas, $C$. vomitoria is common in rural areas. Their ecology and favorite for shaded areas are similar and thus they were expected to occur together (Hall 2001).
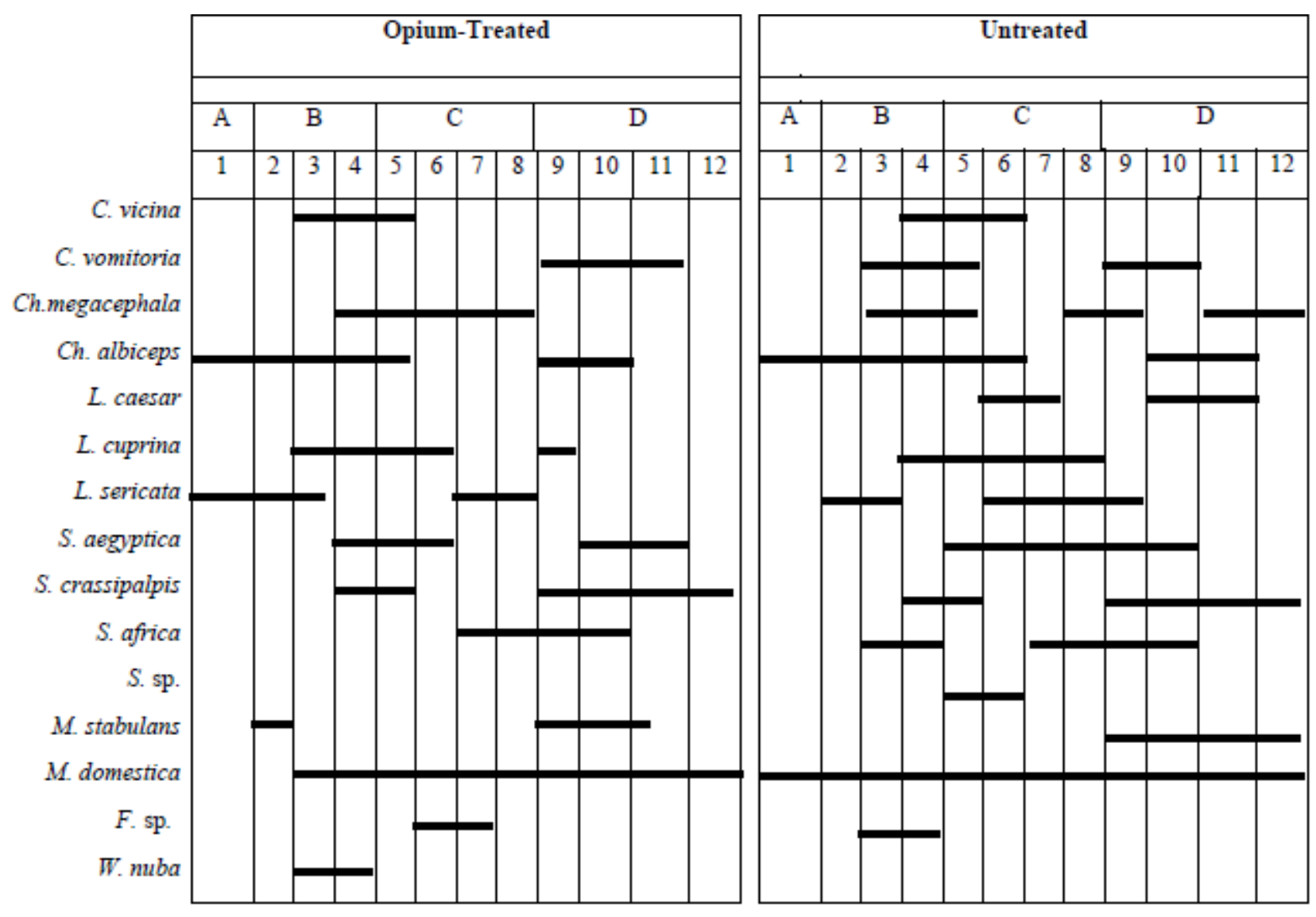

Figure 3. Succession diagram for opium dross-treated and untreated carcasses during 12 sampling intervals (A: Fresh, B: Bloat, C: Decay, D: Post decay) 
In our study, oviposition of $C$. vicina, $C$. vomitoria, and L. sericata occurred in the temperature range of 15 to $39^{\circ} \mathrm{C}$. According to Ody et al. (2017), lower temperature thresholds for oviposition of $C$. vicina, C. vomitoria, and $L$. sericata were $10^{\circ} \mathrm{C}, 16^{\circ} \mathrm{C}$, and $17.5^{\circ} \mathrm{C}$, respectively. The upper-temperature threshold for both $C$. vomitoria and $L$. sericata was $40^{\circ} \mathrm{C}$, whilst the highest temperature at which oviposition occurred in C. vicina was $35^{\circ} \mathrm{C}$.

During the post decay, the larvae started to migrate away from the untreated remains to pupate on day 11 and day 12, and for the treated remains, this started a little earlier on day 10 and day 11 . This may be due to the effect of opium, which may increase the growth rate of some maggots. According to Goff (1991), Heroin decreasing larval development time and increasing the larval growth rate of Boettcherisca peregrina (Diptera, Sarcophagidae). Salimi et al. (2018a) found that the presence of Morphine $(12.5 \mathrm{mg})$ in rabbit tissues retarded larval development time. In this study, we observed that the larvae collected on the treatment carcasses often became adults with deformed wings (Figure 4).

Most species were collected on the remains of untreated rabbits $(53.6 \%)$. Significant difference was not found in the comparison of the number of individuals on treated and untreated carcasses (P: 0.63) (Table 2). Lucilia caesar and W. nuba were recorded exclusively from the remains of untreated and treated rabbits, respectively. Abouzied (2016) analyzed succession data on Diptera on Tramadoltreated rats and showed that tramadol treated carcasses are more favorable for oviposition of Sarcophaga spp., while females of Wohlfahrtia spp. exhibited similar favorites to both tramadols treated and untreated carcasses.

During this study, $M$. domestica appeared on the carcasses at the fresh, bloated, decay, and post decay stages of decomposition, while $M$. stabulans was restricted to the bloated and post decay stages. Abouzied (2014) observed that members of Muscidae were restricted only to the bloated stage. While Wolff et al. (2001) and Al-Mesbah et al. (2012) collected muscids during all stages of decomposition.

In this study, Ch. albiceps (26.2\%), L. sericata (15.9\%), and Musca domestica (13.9\%) were the dominant species on both carcasses types. These three species have been described as the dominant species and the first visitors to the carcass in different studies (Castro et al. 2019; Keshavarzi et al. 2019). Temperature plays a key role in the distribution and dispersion of $C h$. albiceps, and this species mostly reported in the spring and summer (Salimi et al. 2018b). Chrysomy albiceps has been reported as the most dominant species on rabbit carcass collected in four seasons in the eastern region of the Kingdom of Saudi Arabia (Shaalan et al. 2017), and two seasons in Iran (Salimi et al. 2018b). Given that these species are present on both treated and untreated carcasses, they can be used as a good indicator to estimate the time of death.

Diversity analysis showed no significant difference between the Shannon index in treated and untreated carcasses (t: 0.5770, P: 0.56). The mean pairwise taxa similarities (Jaccard coefficient) for insect taxa succession waves for each sampling day are shown in Figures 5.

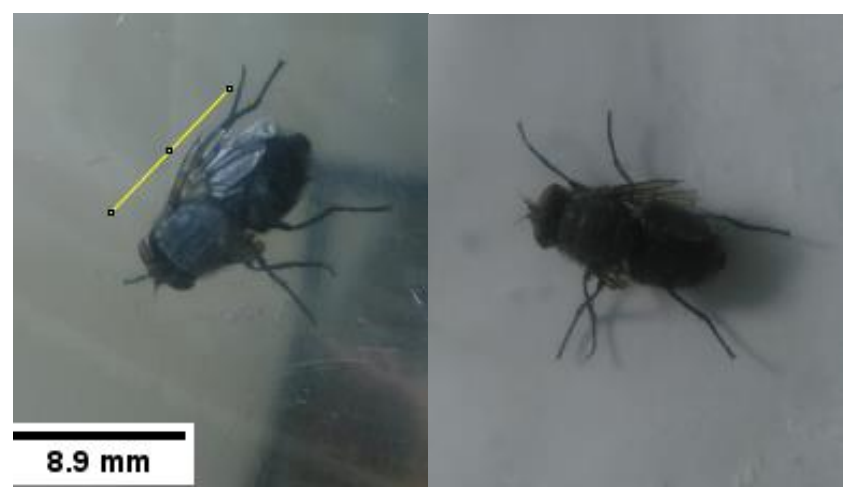

Figure 4. Emerged adult fly species (C.vicina) with deformed wings collected on the treated rabbit carcasses

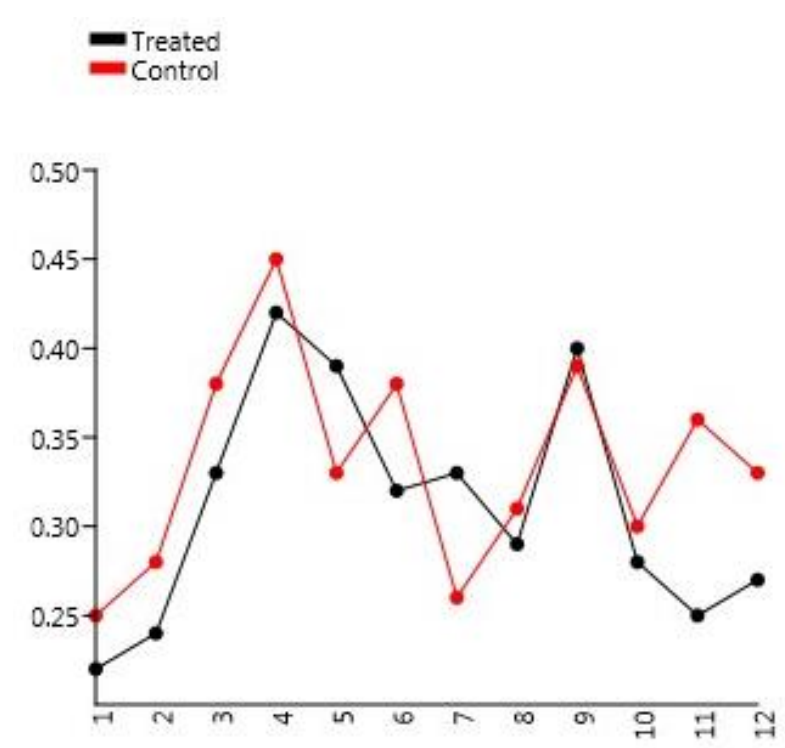

Figure 5. Mean pairwise Jaccard similarities for each sampling interval during the succession of dipteran species on opium dross-treated and untreated carcasses in October 2019

Table 2. The mean number of dipteran species collected on the opium dross treated and untreated rabbit carcasses in October 2019

\begin{tabular}{lccc}
\hline \multicolumn{1}{c}{ Species } & $\begin{array}{c}\text { Opium-treated } \\
\mathbf{N}(\%)\end{array}$ & $\begin{array}{c}\text { Untreated } \\
\mathbf{N}(\%)\end{array}$ & $\begin{array}{c}\text { Total } \\
\mathbf{N}(\%)\end{array}$ \\
\hline Calliphora vicina & $29(42.5)$ & $41(57.5)$ & $70(7.2)$ \\
C. vomitoria & $10(58.9)$ & $7(41.1)$ & $17(1.8)$ \\
Chrysomya megacephala & $43(61.5)$ & $27(38.5)$ & $70(7.2)$ \\
Ch. albiceps & $101(40)$ & $151(60)$ & $252(26.2)$ \\
Lucilia caesar & $0(0)$ & $11(100)$ & $11(1.1)$ \\
L. cuprina & $5(25)$ & $15(75)$ & $20(2.0)$ \\
L. sericata & $80(52)$ & $74(48)$ & $154(15.9)$ \\
Sarcophaga aegyptica & $44(62)$ & $27(38)$ & $71(7.4)$ \\
S. crassipalpis & $12(32.5)$ & $25(67.5)$ & $37(3.9)$ \\
S. africa & $26(66.6)$ & $13(33.4)$ & $39(4.0)$ \\
Sarcophaga sp. & $0(0)$ & $8(100)$ & $8(0.80)$ \\
Muscina stabulans & $24(39.4)$ & $37(60.6)$ & $61(6.3)$ \\
Musca domestica & $57(41.4)$ & $77(58.6)$ & $134(13.9)$ \\
Fannia sp. & $8(53.3)$ & $7(46.7)$ & $15(1.6)$ \\
Wohlfahrtia nuba & $7(100)$ & $0(0)$ & $7(0.73)$ \\
Total & $448(46.4)$ & $518(53.6)$ & $966(100)$ \\
\hline
\end{tabular}


The taxa resemblance values for $12 \mathrm{~d}$ sampling intervals during the summer trials ranged from 0.25-0.44 and 0.23-0.42 for untreated and treated carcasses, respectively. The lowest taxa resemblance was observed on the first day of decomposition, but the greatest resemblance was recorded on day 4. Permutation of similarity analysis was used to test species resemblance values between sampling intervals. The correlation was significant at the 0.05 level (P: 0.04), and therefore the null hypothesis was rejected. These results showed low to medium similarity in species between sampling intervals within each group, similar to Tabor et al. (2005) for ethanol-treated and untreated pigs. The low degree of similarity reveals rapid temporal changes in the composition of the taxa. Consequently, the cadaver as an ecological unit was more stable on day 4.

The permutation statistical analysis conducted on the carcass similarity matrices for all taxa showed that there were no significant differences in the overall dipteran succession between opium-treated and untreated carcasses. Thus, antemortem consumption of opium dross by rabbits did not seem to alter the successional waves of dipteran taxa on the decomposing carcasses. In an identical case, Tabor et al. (2005) found that successional patterns of insect species were similar between ethanol-treated and untreated carcasses. Similar findings have been reported in previous studies of carcasses treated with Organophosphate insecticides (Mahat et al. 2009; Yan-Wei et al. 2010).

Larvae of $C$. vicina, Ch. albiceps, L. sericata, and $M$. domestica could be used as possible taxa for estimation of PMI in the county town of Kazerun, Iran. In the case of opioid (opium) abused cadaver, this substance could not have an effect on the PMI estimation based on the pattern of succession. But it seems that the PMI should be corrected when the estimate is based on larval growth rate. Further study on the effect of opium on the growth rate of the dominant species is valuable.

\section{ACKNOWLEDGEMENTS}

This paper is extracted from parts of the dissertation of DK in medical entomology of Tehran University of Medical Sciences, Tehran, Iran. The author(s) have received financial support from Tehran University of Medical Sciences, Project No. 38345. We would like to thank the Shiraz University of Medical Sciences, Iran for their kindly cooperation.

\section{REFERENCES}

Abouzied EM. 2016. Postmortem attraction of sarcosaprophagous diptera to tramadol-treated rats and morphometric aspects of the developed larvae. Neotrop Entomol 45 (3): 326-332.

Abouzied EM. 2014. Insect colonization and succession on rabbit carcasses in Southwestern Mountains of the Kingdom of Saudi Arabia. J Med Entomol 51 (6): 1168-1174.

Akbarzadeh K, Wallman JF, Sulakova H, Szpila K. 2015. Species identification of Middle Eastern blowflies (Diptera: Calliphoridae) of forensic importance. Parasitol Res 114: 1463-1472.
Alinejad S, Aaseth J, Abdollahi M, Hassanian-Moghaddam H, Mehrpour O. 2018. Clinical aspects of opium adulterated with lead in Iran: A review. Basic Clin Pharmacol Toxicol 122 (1): 56-64.

Al-Mesbah H, Moffatt C, El-Azazy OM, Majeed QA. 2012. The decomposition of rabbit carcasses and associated necrophagous Diptera in Kuwait. Forensic Sci Intl 217 (1-3): 27-31.

Bugelli V, Gherardi M, Focardi M, Pinchi V, Vanin S, Campobasso CP. 2018. Decomposition pattern and insect colonization in two cases of suicide by hanging. Forensic Sci Res 3 (1): 94-102.

Campos-Mañas MC, Ferrer I, Thurman EM, Pérez JA, Agüera A. 2019. Identification of opioids in surface and wastewaters by LC/QTOF-MS using retrospective data analysis. Sci Total Environ 664: 874-884.

Carvalho LM, Linhares AX, Palhares FA. 2012. The effect of cocaine on the development rate of immatures and adults of Chrysomya albiceps and Chrysomya putoria (Diptera: Calliphoridae) and its importance to postmortem interval estimate. Forensic Sci Intl 220 (1): 27-32.

Castro M, Centeno N, González-Vainer P. 2019. An initial study of insect succession on pig carcasses in open pastures in the northwest of Uruguay. Forensic Sci Int. DOI: 10.1016/j.forsciint.2019.05.053.

Concheiro-Guisan M, Chesser R, Pardi J, Cooper G. 2018. Postmortem toxicology of new synthetic opioids. Front Pharmacol 9: 1210. DOI: $10.3389 /$ fphar.2018.01210.

Dahmardehei M, Rafaiee R. 2012. Opium syrup distribution, limitation and challenges. Zahedan J Res Med Sci 14 (6): 48-56.

El-Samad LM, El-Moaty ZA, Makemer HM. 2011. Effects of Tramadol on the development of Lucilia sericata (Diptera: Calliphoridae) and detection of the drug concentration in postmortem rabbit tissues and larvae. J Entomol 8: 353-364.

El-Gawad AA, Badawy RM, El-Bar MM, Kenawy MA. 2019. Successive waves of dipteran flies attracted to warfarin-intoxicated rabbit carcasses in Cairo, Egypt. J Basic Appl Zool 80 (1): 56-66.

Gemmellaro MD, Hamilton GC, Ware JL. 2019. Review of molecular identification techniques for forensically important Diptera. J Med Entomol 56 (4): 887-902.

Goff ML, Brown WA, Hewadikaram K, Omori A. 1991. Effect of heroin in decomposing tissues on the development rate of Boettcherisca peregrina (Diptera, Sarcophagidae) and implications of this effect on estimation of postmortem intervals using arthropod development patterns. J Forensic Sci 36 (2): 537-542.

Hall RD. 2001. Introduction: Perceptions and status of forensic entomology. In: Byrd JH, Castner JL (eds). Forensic Entomology. The Utility of Arthropods in Legal Investigations. CRC Press, Boca Raton, FL.

Hore G, Parui P, Saha GK, Banerjee D. 2017. Variations in colonization and succession pattern of dipteran flies of forensic importance on Indian mole-rat carcasses in urban and suburban localities of Kolkata, West Bengal: Implications in corpse relocation studies. Malays J Med Sci 1 (3): 52-62.

Jamalian M, Nasrollahzadeh M, Kazemifar AM, Solhi H. 2019. Comparing Methadone and Tincture of opium for the management of opioid withdrawal among subjects with an opioid use disorder. J Pharm Res Intl 1: 10-17.

Keshavarzi D, Zaimy MA, Yusuf MA, Shahriarinamadi M, Parkhideh S. 2019. Insect succession on carrion in Fars Province, Southwestern Iran. Egypt J Forensic Sci 9 (1): 18-25

Khoobdel M, Keshavarzi D, Sobati H, Akbari M. 2020. Species diversity, habitat and abundance of Culicid mosquitoes in Bushehr Province, South of Iran. Biodiversitas 21 (4): 1401-1406.

Li Q, Ramasamy S, Singh P, Hagel JM, Dunemann SM, Chen X, Chen R, Yu L, Tucker JE, Facchini PJ, Yeaman S. Gene clustering and copy number variation in alkaloid metabolic pathways of opium poppy. Nature Commun 11 (1): 1-3.

Magni PA, North JD, Zwerver M, Dadour IR. 2019. Insect succession pattern on decomposing pig carcasses in Tasmania. Pap Proc R Soc Tasmania 153: 31-36.

Mahat N, Zafarina Z, Jayaprakash P. 2009. Influence of rain and malathion on the oviposition and development of blowflies (Diptera: Calliphoridae) infesting rabbit carcasses in Kelantan, Malaysia. Forensic Sci Intl 192 (1-3): 19-28.

Martín-Vega D, Nieto CM, Cifrián B, Baz A, Díaz-Aranda LM. 2017. Early colonisation of urban indoor carcasses by blow flies (Diptera: Calliphoridae): An experimental study from central Spain. Forensic Sci Intl 278: 87-94.

Mashaly AMA, Al-Mekhlafi FA. 2016. Differential Diptera succession patterns on decomposed rabbit carcasses in three different habitats. $\mathbf{J}$ Med Entomol 53 (5): 1192-1197. 
Moezi SA, Azdaki N, Kazemi T, Moghaddam H, Partovi N, Hamidi F, Hanafi-Bojd N, Jafarnejad M, Nakhaee S. 2019. Effects of opium use on cardiovascular mortality: A critical appraisal of a topic. Iran J Public Health 48 (10): 1937-1939.

Ody H, Bulling MT, Barnes KM. 2017. Effects of environmental temperature on oviposition behavior in three blow fly species of forensic importance. Forensic Sci Intl 275: 138-143.

Oesterle TS, Kolla BP, Rummans TA, Gold MS. 2020. Medicationassisted therapies for opioid use disorders in patients with chronic pain. J Neurol Sci. DOI: 10.1016/j.jns.2020.116728.

Ren L, Shang Y, Chen W, Meng F, Cai J, Zhu G, Chen L, Wang Y, Deng J, Guo Y. 2018. A brief review of forensically important flesh flies (Diptera: Sarcophagidae). Forensic Sci Res 3 (1): 16-26.

Salimi M, Rassi Y, Ahmadi B, Chatrabgoun O, Jamshidi R, Rafizadeh S. 2018a. Effects of morphine on the biomass and development rate of Chrysomya albiceps (Diptera: Calliphoridae), a forensically important species. Tropical Biomed 35 (2): 560-570.

Salimi M, Chatrabgoun O, Akbarzadeh K, Oshaghi M, Falahati MH, Rafizadeh S, Yusuf MA, Rassi Y. 2018b. Evaluation of insect succession patterns and carcass weight loss for the estimation of postmortem interval. J Med Entomol 55 (6): 1410-1422.

Shaalan EA, El-Moaty ZA, Abdelsalam S, Anderson GS. 2017. A preliminary study of insect succession in Al-Ahsaa Oasis, in the eastern region of the Kingdom of Saudi Arabia. J Forensic Sci 62: 239-243.

Shahbazi F, Mirtorabi SD, Ghadirzadeh MR, Hashemi-Nazari SS, Barzegar A. 2017. Characterizing mortality from substance abuse in Iran: An epidemiological study during March 2014 to February 2015 Addict Health 9 (3): 166-174.
Siste K, Nugraheni P, Christian H, Suryani E, Firdaus KK. 2019. Prescription drug misuse in adolescents and young adults: An emerging issue as a health problem. Curr Opin Psychiatry 32 (4): 320 327.

Sugihartati R, Susilo D. 2019. Acts against drugs and narcotics abuse: Measurement of the effectiveness campaign on Indonesian narcotics regulator Instagram. J Drug Alcohol Res 8 (2): 1-4.

Szpila K, Richet R, Pape T. 2015. Third instar larvae of flesh flies (Diptera: Sarcophagidae) of forensic importance-critical review of characters and key for European species. Parasitol Res 114 (6): 2279 2289.

Tabor KL, Fell RD, Brewster CC, Pelzer K, Behonick GS. 2005. Effects of antemortem ingestion of ethanol on insect successional patterns and development of Phormia regina (Diptera: Calliphoridae). J Med Entomol 42 (3): 481-489.

Wang M, Chu J, Wang Y, Li F, Liao M, Shi H, Zhang Y, Hu G, Wang J 2019. Forensic entomology application in China: Four case reports. J Forensic Leg Med 63: 40-47.

Wang Y, Ma MY, Jiang XY, Wang JF, Li LL, Yin XJ, Wang M, Lai Y, Tao LY. 2017. Insect succession on remains of human and animals in Shenzhen, China. Forensic Sci Intl 271: 75-86.

Wolff M, Uribe A, Ortiz A, Duque P. 2001. A preliminary study of forensic entomology in Medellin, Colombia. Forensic Sci Intl 120: 53-59.

Yan-Wei S, Xiao-Shan L ,Hai-Yang W, Run-Jie Z. 2010. Effects of malathion on insect succession and the development of Chrysomya megacephala (Diptera: Calliphoridae) in the field and implications for estimating postmortem interval. Am J Forensic Med Pathol 31 (1): 46-51. 